\title{
PERBEDAAN LAMA PELEPASAN TALI PUSAT BAYI BARU LAHIR DENGAN BENANG TALI DAN UMBILICAL CORD CLEM
}

\author{
Dewi Mayangsari ${ }^{1}$, Eka Nining Setyawati $^{2}$ \\ ${ }^{1}$ STIKes Karya Husada Semarang \\ E-mail:_mayang_yahud@yahoo.co.id
}

\begin{abstract}
ABSTRAK
Lamanya pelepasan sisa tali pusat bervariasi, yaitu dalam waktu 3 hari, 5 hari, 7 hari, bahkan ada yang sampai 2 minggu. Semakin lama pelepasan tali pusat menunjukkan lamanya waktu yang digunakan untuk penyembuhan luka akibat pemotongan tali pusat, yang berarti semakin terbukanya menimbulkan infeksi pada bayi. Banyaknya faktor yang mempengaruhi lepasnya sisa tali pusat salah satuny yaitu cara pengikatan tali pusat. Tujuan dari penelitian ini adalah untuk mengetahui perbedaan lama pelepasan tali pusat pada bayi baru lahir dengan menggunakan benang tali dan umbilical cord clem di BPM Mulyani. Penelitian ini merupakan jenis penilitian Pra Experiment dengan rancangan post test only design dengan pendekatan waktu retrospektif. Teknik pengumpulan data dengan melakukan pengumpulan dari data catatan medis pasien di BPM Mulyani dengan jumlah sampel adalah 30 pasien. Hasil penelitian menunjukkan bahwa Pemutusan tali pusat dengan umbilical cord clem rata-rata memiliki waktu pengelepasan talipusat 4.20 hari. Pemutusan tali pusat dengan benang tali pusat rata-rata memiliki waktu pengelepasan talipusat 7.27 hari. Terdapat perbedaan lama pelepasan tali pusat umbilical cord clem dengan benang tali pusat di BPM Mulyani dengan nilai $p$-value 0,000 .
\end{abstract}

Kata Kunci: Pengikatan; benang tali ; umbilical cord clem

\section{DIFFERENCES IN OLD RELEASE OF NEWBORN CENTERS NEWBORNS BORN WITH YARN STRAPS AND UMBILICAL CORD CLEM}

\begin{abstract}
The duration of the rest of the umbilical cord varies, ie within 3 days, 5 days, 7 days, and some even up to 2 weeks. The longer the release of the umbilical cord indicates the length of time spent on wound healing due to umbilical cord cut, which means that the opening of the infection is more likely to infect the infant. The number of factors that affect the release of the rest of the umbilical cord is a way of binding the umbilical cord. The purpose of this research is to know the difference of old umbilical release on newborn by using string thread and umbilical cord clem at BPM Mulyani. This research is a type of Pre Experiment research with post test only design design with retrospective time approach. Data collection techniques by collecting data from medical records of patients in BPM Mulyani with the number of samples is 30 patients. The results showed that umbilical cord clem rupture had an average of 4.20 days of wheel release time. Halting of the umbilical cord with an average umbilical cord has a 7.27 day thoracic removal time. There is a difference of umbilical cord clem release length with umbilical cord in BPM Mulyani with p-value 0,000
\end{abstract}

Keywords: Binding; string thread; umbilical cord clem

Jurnal SMART Kebidanan Sekolah Tinggi Ilmu Kesehatan (STIKes) Karya Husada Semarang

www.stikesyahoedsmg.ac.id/ojs/index.php/sjkb 


\section{Pendahuluan}

Tali pusat atau umbilical cord adalah saluran kehidupan bagi janin selama dalam kandungan yang selama 9 bulan 10 hari menyuplai zat-zat gizi dan oksigen janin. Tali pusat (funikulus umbilikalis), disebut juga funis merentang dari umbilikus janin ke permukaan fetal plasenta dan mempunyai panjang $50-55 \mathrm{~cm}$ (Sodikin, 2009). Pemotongan dan pengikatan tali pusat segera setelah bayi lahir menyebabkan pemisah fisik terakhir antara ibu dan bayi. Dan ini sangat tergantung dari pengalaman seorang ahli kebidanan (Sumarah, 2009).

Kematian bayi berkisar $40 \%$ terjadi pada bulan pertama kehidupan. Infeksi merupakan penyebab kesakitan dan kematian yang sering terjadi pada masa neonatal (Kementrian Kesehatan R.I, 2009). Infeksi yang sering terjadi pada masa neonatal diantaranya infeksi pada tali pusat yang biasanya terjadi karena tali pusat yang belum lepas dan basah serta perawatan tali pusat yang kurang bersih.

Lamanya pelepasan sisa tali pusat bervariasi, yaitu dalam waktu 3 hari, 5 hari, 7 hari, bahkan ada yang sampai 2 minggu. Semakin lama pelepasan tali pusat menunjukkan lamanya waktu yang digunakan untuk penyembuhan luka akibat pemotongan tali pusat, yang berarti semakin terbukanya menimbulkan infeksi pada bayi (Gultom, 2004).

Cara pengikatan tali pusat sekarang ini semakin berkembang. Seiring dengan perkembangan teknologi, terdapat beberapa alat yang digunakan, yaitu dapat menggunakan umbilical cord clem dan menggunakan benang tali pusat. Selanjutnya yang menjadi pertanyaan adalah jika seluruh prosedur dan teknik pelayanan perawatan tali pusat dilaksanakan dengan seksama tetapi pengikatannya dilakukan dengan alat yang berbeda, dilihat dari sisi waktu lebih efektif menggunakan umbilical cord clem ataukah menggunakan benang tali pusat.

Dari survey pendahuluan yang dilakukan peneliti diambil 15 responden secara acak, bayi baru lahirnya dilakukan pengikatan tali pusat dengan umbilical cord clem dan yang menggunakan benang tali pusat. Dilakukan pengikatan tali pusat menggunakan benang katun steril bilamana ibu yang akan bersalin diantar oleh dukun bayi dan atas permintaan dukun bayi tersebut agar bayi yang lahir nanti pengikatan tali pusatnya menggunakan benang katun steril, dengan alasan perawatan tali pusat selanjutnya lebih mudah dan tidak menimbulkan bekas umbilical cord clem di perut bayi. Pengikatan tali pusat menggunakan umbilical cord clem bila ibu yang akan bersalin tidak diantar dukun bayi.Pada pelepasan tali pusat yang lama menimbulkan masalah pada ibu bayi tersebut, diantaranya kecemasan dan perawatan tali pusat yang berkepanjangan. 
Dengan adanya permasalahan di atas, mendorong penulis untuk mencoba mengadakan penelitian mengenai perbedaan lama pelepasan tali pusat pada bayi baru lahir dengan menggunakan benang tali dan umbilical cord clem di BPM Mulyani.

\section{Tinjauan Teoritis}

\section{Bayi Baru Lahir}

a. Pengertian Bayi Baru lahir

Bayi baru lahir normal adalah bayi yang lahir dalam presentasi belakang kepala melalui vagina tanpa memakai alat, pada usia kehamilan genap 37 minggu sampai dengan 42 minggu, dengan berat badan 2500 - 4000, nilai apgar > 7 tanpa cacat bawaan (Pusat Pengembangan Keperawatan Carolus, 2008).

\section{Tali Pusat}

a. Pengertian tali pusat

Tali pusat atau Umbilical cord adalah saluran kehidupan bagi janin selama dalam kandungan, dikatakan saluran kehidupan karena saluran inilah yang selama 9 bulan 10 hari menyuplai zat - zat gizi dan oksigen janin.

b. Pemotongan Tali Pusat

Pemotongan dan pengikatan tali pusat menyebabkan pemisahan fisik terakhir antara ibu dan bayi dan ini sangat tergantung dari pengalaman seorang ahli kebidanan (Sumarah, 2009). Pengikatan tali pusat dengan beberapa cara:

1. Alat penjepit plastik, yang khusus dibuat untuk tali pusat (disposible) dipasang $1 \mathrm{~cm}$ dibawah alat penjepit yang sudah dipasang lebih dahulu. Alat penjepit plastik ini tetap memberikan tekanan pada tali pusat, walaupun Jeli Wharton (Wharton's jelly) mengkerut dan kemudian dibuang bersamaan dengan lepasnya tali pusat

2. Pita dari bahan nilon yang sangat kuat dan yang disimpan dalam bungkus steril diikatkan rangkap pada tali pusat seerat-eratnya sehingga tidak mudah lepas, dan terus menekan tali pusat, walaupun jeli Wharton sudah kering. Pita ini dibuang bersamaan dengan lepasnya tali pusat.

3. Benang katun steril diikatkan rangkap dua pada tali pusat. Pengikatan dengan benang katun steril ini tidak menjamin penekanan yang terus menerus pada tali pusat. Walaupun pada permulaan ikatannya sudah baik, tetapi karena tali pusat mengkerut, ikatan bisa menjadi longgar sehingga memungkinkan terjadinya perdarahan. Untuk Jurnal SMART Kebidanan Sekolah Tinggi Ilmu Kesehatan (STIKes) Karya Husada Semarang 
mencegah hal yang tidak diinginkan inilah harus dilakukan observasi yang berulangulang pada waktu tertentu selama 48 jam. Perdarahan tidak mungkin terjadi pada pemakaian alat penjepit plastik dan pita nilon karena terjadi penekanan yang terusmenerus pada tali pusat.

\section{Metode Penelitian}

Penelitian ini merupakan jenis penilitian Pra Experiment dengan rancangan post test only design, dengan rancangan ini peneliti akan melakukan pengukuran lama pelepasan tali pusat pada dua kelompok responden, yaitu kelompok dengan benang dan kelompok dengan umbilical cord clem. Penelitian ini dilaksanakan di BPM Mulyani. Penelitian dilaksanakan bulan Desember 2011. Variabel Penelitian ada dua, yaitu variabel bebas (independent) adalah cara penjepitan tali pusat pada bayi baru lahir yang menggunakan benang tali pusat dan umbilical cord clem dan variabel terikat (dependent) adalah lama pelepasan tali pusat. Populasi dalam penelitian ini adalah semua bayi baru lahir yang umur kehamilannya aterm dengan persalinan normal dan lahir di Bidan Praktek Mandiri Mulyani, yaitu pada bulan Juli sampai dengan Oktober 2015 ada 30 bayi. Sampel yang digunakan adalah 30 responden. Cara pengambilan sampel dalam penelitian ini adalah dengan teknik total sampling atau sampling jenuh. Alat - alat yang digunakan untuk mengumpulkan data menggunakan instrumen lembar observasi tentang perawatan tali pusat dengan umbilical cord clem dan benang tali pusat. Analisis bivariat dilakukan dengan uji Mann Whitney

\section{Hasil Penelitian}

Dari proses pengumpulan data primer yang diperoleh dari pengisian kuesioner oleh 30 responden yang melakukan proses persalinan di BPM Mulyani didapatkan hasil data perawatan tali pusat dan lama pelepasan tali pusat yang diolah dan dilakukan uji statistik dengan hasil sebagai berikut:

1. Lama pelepasan tali pusat dengan umbilical cord clem

Tabel 1 Distribusi frekuensi lama pelepasan tali pusat dengan umbilical cord clem di BPM Mulyani

\begin{tabular}{ccccc}
\hline Variabel & $\mathrm{n}$ & Mean & SD & Min-Max \\
\hline Lama pelepasan tali pusat & 15 & 4.20 & 1.082 & $3-6$ \\
dengan umbilical cord clem & & & & \\
\hline
\end{tabular}


Tabel 1 menunjukkan bahwa dari 15 responden yang telah melakukan pemutusan tali pusat dengan umbilical cord clem rata-rata memiliki waktu pelepasan talipusat 4.20 hari dengan frekuensi waktu tercepat selama 3 hari dan terlama 6 hari, dengan standar deviasi sebesar 1.082 .

2. Lama pelepasan tali pusat dengan benang tali pusat

Tabel 2 Distribusi frekuensi lama pelepasan tali pusat dengan umbilical cord clem di BPM Mulyani

\begin{tabular}{ccccc}
\hline Variabel & $\mathrm{n}$ & Mean & SD & Min-Max \\
\hline $\begin{array}{c}\text { Lama pelepasan tali pusat } \\
\text { dengan benang tali pusat }\end{array}$ & 15 & 7.27 & 1.486 & $5-10$ \\
\hline
\end{tabular}

Tabel 2 menunjukkan bahwa dari 15 responden yang telah melakukan pemutusan tali pusat dengan benang tali pusat rata-rata memiliki waktu pelepasan talipusat 7.27 hari dengan frekuensi waktu tercepat selama 5 hari dan terlama 10 hari, dengan standar deviasi sebesar 1.486 .

3. Perbedaan lama pelepasan tali pusat umbilical cord clem dengan benang tali pusat Berdasarkan dari data univariat kemudian dilakukan analisa perbedaan lama pelepasan tali pusat umbilical cord clem dengan benang tali pusat bayi di BPM Mulyani Demak dengan independent t-test yang memiliki syarat data semua variable berdistribusi normal. Dari hasil analisis normalitas data dengan uji Shapiro-wilk (uji normalitas pada jumlah sampel kecil) diketahui bahwa hanya pada variabel lama pelepasan tali pusat dengan benang tali pusat yang memiliki distribusi data yang normal ( $p$ value:0.540), sedangkan pada variabel lama pelepasan tali pusat dengan umbilical cord clem data tidak berdistribusi normal ( $p$ value:0.006) sehingga uji statistik yang digunakan adalah uji alternatif Mann-whitney test. Mann-whitney test didapatkan hasil sebagai berikut:

Tabel 3 Perbedaan lama pelepasan tali pusat umbilical cord clem dengan benang tali pusat

\begin{tabular}{lcccc}
\hline & $\mathrm{n}$ & Rata-rata & $\mathrm{Z}$ & $p$-value \\
\hline umbilical cord clem & 15 & 4.20 & -4.246 & 0.000 \\
benang tali pusat & 15 & 7.27 & & \\
Total & 30 & & & \\
\hline
\end{tabular}

Jurnal SMART Kebidanan Sekolah Tinggi Ilmu Kesehatan (STIKes) Karya Husada Semarang 
Berdasarkan tabel 3 diketahui bahwa pada variable umbilical cord clem memiliki waktu pelepasan dengan nilai rata - rata 4.20 hari, sedangkan pada variabel benang tali pusat memiliki waktu pelepasan dengan nilai rata - rata 7.27 hari.

Hasil uji Mann Whitney diperoleh nilai $p$-value $0,000(p<0,05)$ maka Ho ditolak yang berarti terdapat perbedaan lama pelepasan tali pusat umbilical cord clem dengan benang tali pusat di BPM Mulyani.

\section{Pembahasan}

1. Lama pelepasan tali pusat dengan umbilical cord clem

Hasil penelitian menunjukkan bahwa pemutusan tali pusat dengan umbilical cord clem rata-rata memiliki waktu pelepasan talipusat 4.20 hari dengan frekuensi waktu tercepat selama 3 hari dan terlama 6 hari. Dari hasil penelitian menunjukkan bahwa Lama pelepasan tali pusat degan umbilical cord clem kurang dari 7 hari dengan hal ini masih sesuai dengan teori yang menjelaskan bahwa tali pusat umumnya berwarna kebiru-biruan dan panjang sekitar 2,5-5 cm segera setelah dipotong. (Meiliya \& Karyuni, 2008, p.165). Lebih cepatnya proses pelepasan tali pusat dengan penggunaan umbilical cord clem dari toleransi waktu yang ditentukan yaitu maksimal 15 hari dikarenakan system kerja alat penjepit plastik umbilical ini yaitu tetap memberikan tekanan pada tali pusat, walaupun Jeli Wharton (Wharton's jelly) mengkerut sehingga tidak memungkinkan kendor dan juga perdarahan tidak mungkin terjadi pada pemakaian alat penjepit plastik dan pita nilon karena terjadi penekanan yang terus-menerus pada tali pusat.

2. Lama pelepasan tali pusat dengan benang tali pusat

Hasil penelitian menunjukkan bahwa pemutusan tali pusat dengan benang tali pusat rata-rata memiliki waktu pelepasan talipusat 7.27 hari dengan frekuensi waktu tercepat selama 5 hari dan terlama 10 hari. Penjepit tali pusat digunakan untuk menghentikan perdarahan. Penjepit tali pusat ini dibuang ketika tali pusat sudah kering, biasanya sebelum ke luar dari rumah sakit atau dalam waktu dua puluh empat jam hingga empat puluh delapan jam setelah lahir. Sisa tali pusat yang masih menempel di perut bayi (umbilical stump), akan mengering dan biasanya akan terlepas sendiri dalam satu minggu setelah lahir dan luka akan sembuh dalam 15 hari (Meiliya \& Karyuni, 2008, p.165).

Jurnal SMART Kebidanan Sekolah Tinggi Ilmu Kesehatan (STIKes) Karya Husada Semarang 
Lamanya pelepasan dengan teknik benang tali pusat dikarenakan Pengikatan dengan benang katun steril ini tidak menjamin penekanan yang terus menerus pada tali pusat. Walaupun pada permulaan ikatannya sudah baik, tetapi karena tali pusat mengkerut, ikatan bisa menjadi longgar sehingga memungkinkan terjadinya perdarahan. Untuk mencegah hal yang tidak diinginkan inilah harus dilakukan observasi yang berulang-ulang pada waktu tertentu selama 48 jam

3. Hubungan pengikatan tali pusat dengan lama pelepasan tali pusat

Berdasarkan Hasil uji Mann Whitney diperoleh nilai $p 0,000(p<0,05)$ maka Ho ditolak yang berarti terdapat perbedaan lama pelepasan tali pusat umbilical cord clem dengan benang tali pusat di BPM Mulyani tahun 2011. Hasil terdapat perbedaan pada penelitian ini dikarenakan adanya fakta bahwa penggunaan klem umbilical cord memiliki frekuensi kejadian lebih banyak pada pelepasan tali pusat pada kategori cepat sedangkan dengan teknik penggunaan benang tali pusat mempunyai frekuensi kejadian lepasnya tali pusat lebih lama. Hasil penelitian ini juga dipertegas oleh pendapat Sumarah (2009) yang menjelaskan bahwa penggunaan alat penjepit plastik, yang khusus dibuat untuk tali pusat (disposible) dapat memberikan tekanan pada tali pusat, walaupun Jeli Wharton (Wharton's jelly) mengkerut.

\section{Kesimpulan}

Pelepasan tali pusat dengan benang tali pusat membutuhkan waktu lebih lama dibandingkan dengan umbilical cord clem.

\section{Saran}

Diharapkan puskesmas setempat selaku perpanjangan tangan dari dinas kesehatan dapat memberikan informasi kesehatan berkaitan dengan keputusan penggunaan umbilical cord clem dalam pengikatan tali pusat. Sebaiknya tenaga kesehatan khususnya bidan memilih penggunaan umbilical cord clem untuk pengikatan tali pusat agar proses pelepasan tali pusat dapat berlangsung lebih cepat. 


\section{Daftar Pustaka}

Dinkes Jateng. 2006. Profil Kesehatan.

Dinkes Kota Semarang. 2008. Profil Kesehatan.

Hidayat. 2008. Pengantar Ilmu Kesehatan Anak untuk Pendidikan Bidan. Jakarta: EGC

Jitowijoyo \& Kristiyanasari, 2010, Perawatan Tali Pusat, available up http://jtptunimus.com diakses tanggal 1 januari 2012

Notoatmodjo, Soekidjo. 2005. Metodologi Penelitian Kesehatan. Jakarta : PT Rineka Cipta

Novyana. 2010. Penanganan Bayi Baru Lahir.http://novyana.wordpress.com/penanganan-bayibaru-lahir/

Riwidikdo, Handoko. 2009. Statistik Kesehatan. Jokjakarta : Mitra Cendekia Press

Saifudin, 2002. Panduan Praktis Pelayanan Kesehatan Maternal dan Neonat. Jakarta: YBPSP.

Sodikin. 2009. Perawatan Tali Pusat. Jakarta : EGC.

Ummu Kautsar. 2010. Bayi baru Lahir (BBL) Normal. http://ummukautsar.wordpress.com (20 Januari 2010). 